\title{
Atendimento Psicológico ao PaCiente Cirúrgico: AsPeCtos PSicológicos do TRATAMENTO DE DiABÉTICOS DO TIPO I - SPAC/GSI/HUAP
}

\author{
Fernanda Brito ${ }^{\star}$ \\ Roberta Freire Cardoso Meirelles \\ José Henrique Valentim ${ }^{\star \star}$ \\ Paulo Roberto Mattos da Silva $a^{\star \star}$
}

Palavras-Chave: Diabetes. Atendimento psicológico. Perfil do diabético tipo I.

InTRodução: Este trabalho foi elaborado no âmbito do Projeto Permanente de Extensão "Serviço de Psicologia da Área Cirúrgica - GSI/HUAP" (Atendimento psicológico a pacientes cirúrgicos), desenvolvido de forma ininterrupta, desde 1987 sob a coordenação dos professores Paulo Mattos e José $\mathrm{H}$. Valentim e tem a perspectiva de integrar, desde uma matriz de trabalho extensionista, as dimensões de ensino, tanto na esfera da graduação quanto da pós-graduação, e a pesquisa de forma continuada. Visa-se aqui a formulação de estratégias produtivas para minimizar os efeitos da diabetes Tipo 1 na vida de crianças e adoles-centes.

OвJETIVos: a) Promover o acompanhamento psicológico regular dos pacientes diabéticos do Tipo 1 atendidos pelo setor de endocrinologia do HUAP; b) Estabelecer uma descrição biopsicossocial da clientela atendida pelo programa. c) Analisar os impasses que dificultam a implementação do tratamento adequado da patologia; d) Pesquisar os aspectos psíquicos em jogo na relação do sujeito com sua doença e tratamento; e) Estabelecer elementos passíveis de gerar formas mais produtivas de o sujeito e seus familiares lidarem com sua doença.

Metodologia: Atendimento a pacientes inscritos no programa de tratamento multidisciplinar da diabetes Tipo I, discussão e supervisão de casos.

Resultados: Mapeamento das características psicossociais dos portadores de diabetes Tipo I e estabelecimento de estratégias de intervenção para o atendimento a este tipo de paciente.

^ Estagiários do SPAC e alunos do Curso de Graduação em Psicologia da UFF.

$\star \star$ Professor Adjunto do Depto. de Psicologia da UFF e coordenador do SPAC. Endereço: Av. Visconde do Rio Branco s/no, Campus do Gragoatá, Bloco "O" sala 310 - São Domingos, Niterói - RJ. Tel.: (21) 26295018.

E-mail: valentim@vm.uff.br

${ }^{\star \star \star}$ Professor Adjunto do Depto. de Psicologia da UFF e coordenador do SPAC. 